\title{
A Consultoria Interna de Recursos Humanos como Prática Catalisadora da Gestão do Conhecimento Organizacional
}

\author{
Dante Marciano Girardi ${ }^{1}$ \\ Édis Mafra Lapolli \\ Kelly Cristina Benetti Tonani Tosta ${ }^{3}$
}

\section{Resumo}

Este artigo objetiva analisar a contribuição da Consultoria Interna de Recursos Humanos para a Gestão do Conhecimento nas indústrias catarinenses de grande porte. Os procedimentos metodológicos seguiram a linha qualitativa, por meio da pesquisa descritiva e aplicada. Foram entrevistadas sete das maiores empresas catarinenses em número de funcionários. Utilizou-se análise documental e de conteúdo. Quanto aos resultados, a consultoria interna auxilia principalmente nas etapas de socialização e externalização do conhecimento. Além disso, se implementada na sua totalidade e dada autonomia ao consultor interno, permite uma maior interação nos níveis individual, grupal e organizacional descritos por Sabbag (2007). Assim, pode-se perceber que as empresas que possuem maior grau de autonomia, bem como maior nível de implementação são aquelas que os processos são mais compartilhados, socializados e internalizados pelos funcionários. Dessa forma, pode-se afirmar que, nas empresas analisadas, o desenvolvimento dos processos de $\mathrm{CIRH}$ catalisa os resultados da Gestão do Conhecimento nas mesmas.

Palavras-chave: Gestão de pessoas. Consultoria Interna de Recursos Humanos. Gestão do Conhecimento.

\footnotetext{
${ }^{1}$ Doutor em Engenharia e Gestão do Conhecimento pelo PPEGC/UFSC. Professor do Departamento de Ciências da Administração da Universidade Federal de Santa Catarina. Endereço: Universidade Federal de Santa Catarina. Centro Sócio-Econômico. Departamento de Ciências da Administração. Campus Universitário, Bairro Trindade, Florianópolis, SC. Caixa Postal:476. CEP: 88040-900. E-mail: dante.girardi@terra.com.br.

${ }^{2}$ Doutora em Engenharia de Produção pelo PPGEP/UFSC e Pós-Doutora em Sistemas de Informações pela Université de Mompellier II. Professora do Programa de Pós-Graduação em Engenharia e Gestão do Conhecimento da Universidade Federal de Santa Catarina. Endereço: Ria Duarte Schutel, n 100, Apt ${ }^{\circ}$ 502, CEP 88015-600. Florianópolis, SC. E-mail: edismafra@gmail.com.

${ }^{3}$ Doutoranda em Engenharia e Gestão do Conhecimento pelo PPEGC/UFSC. Endereço: NUPERH - Universidade Federal de Santa Catarina. Centro Sócio-Econômico. Departamento de Ciências da Administração. Campus Universitário, Bairro Trindade, Florianópolis, SC. Caixa Postal: 476. CEP: 88040-900. E-mail: kellyadm@hotmail.com. Artigo recebido em: 17/04/2009. Aceito em: 23/08/2009. Membro do Corpo Editorial Científico responsável pelo processo editorial: Thomas G. Brashear.
} 


\section{Introdução}

O conhecimento é inerente ao aprendizado e ao desenvolvimento e a globalização transformou-o em fator básico para a competitividade organizacional.

Novas estruturas, formas de gestão, tecnologias, processos, sistemas, maior ênfase nas pessoas, na informação e na comunicação contribuem para a criação do conhecimento organizacional, tanto quanto resultam do conhecimento. Essa é a atuação das organizações na busca pela competitividade.

Organizações de todos os portes e setores vêm trabalhando o conhecimento de acordo com as suas necessidades, percepções, recursos e projetos futuros. A cultura, nesse sentido, é aspecto determinante da visão e dos valores da organização, a qual gradativamente vai focalizando o conhecimento como ferramenta para a criatividade, a inovação e, então, para o desenvolvimento organizacional.

Há diferentes formas de se atuar na criação do conhecimento nas organizações. É inquestionável o fato de que a organização deve buscar a melhor forma de criar conhecimento. Nesse contexto, todas as áreas da empresa podem contribuir para a construção de um processo contínuo de criação e desenvolvimento do conhecimento.

Por trabalhar com pessoas, que são os recursos diferenciais de uma organização, a área de Recursos Humanos - RH é capaz de gerar conhecimento e desenvolver a organização por meio dos seus processos e da Gestão do Capital Intelectual. Dessa forma, as pessoas são efetivamente incluídas no processo de geração do conhecimento.

Por meio da interação da organização com os indivíduos, as organizações são capazes de criar conhecimento, transformando-se em "empresas criadoras do conhecimento". (NONAKA; TAKEUCHI, 1997, p. 21). O conhecimento genuíno está sempre associado às pessoas, porque a criação do conhecimento começa pelo indivíduo. A Gestão do Conhecimento veio para que as organizações encontrem as melhores formas de mobilizar e alavancar o conhecimento individual e integrá-lo ao conhecimento organizacional (FIGUEIREDO, 2005).

A Gestão do Conhecimento e a Administração de Recursos Humanos evoluem de acordo com as mudanças no ambiente, marcado por diversos fatos que impactaram nas organizações. Paradigmas tradicionais vêm sendo 
reavaliados com o intuito de transformar os modelos de gestão, em especial o modo de gerir as pessoas.

A Consultoria Interna de Recursos Humanos - CIRH tem sido a maneira encontrada para buscar mais agilidade nos processos de Gestão de Pessoas, diante da visão fragmentada e departamental das organizações. Essa é uma abordagem recente dentro da Gestão de Pessoas nas organizações contemporâneas, ampliando a atuação na busca constante do conhecimento $e$ da inovação.

Essa busca se reflete nas principais finalidades dos investimentos realizados pela indústria catarinense até 2010 que, segundo dados da Federação das Indústrias do Estado de Santa Catarina - FIESC (2008), trata-se da aquisição de máquinas e equipamentos e da atualização tecnológica. $\mathrm{Na}$ sequência de prioridades aparece o aumento da capacidade produtiva $e$ o desenvolvimento de produtos. Sendo assim, percebe-se a preocupação dos industriais catarinenses em se modernizar, ampliar produção e inovar.

Cabe também destacar que as atividades industriais com melhor desempenho no ano de 2007, no Estado de Santa Catarina, foram a fabricação de máquinas, aparelhos e materiais elétricos, pois obtiveram um incremento da produção de $14,34 \%$ em relação ao de 2006. A FIESC (2008) afirma que desde o ano 2000, quando a produção industrial de máquinas e equipamentos do Brasil cresceu $18,85 \%$, a produção não havia crescido tanto.

Com relação ao capital humano, o emprego formal brasileiro, em 2007, de acordo com os dados do Ministério do Trabalho e Emprego (MTE apud FIESC, 2008), apresentou significativa expansão, com a criação de 1.617.392 postos de trabalho celetistas, o que resulta em um crescimento na ordem de $5,85 \%$. No Estado de Santa Catarina, o aumento foi ainda mais significativo: $6,11 \%$ no emprego formal, totalizando 83,6 mil postos de trabalho adicionais.

Nesse contexto, tem-se como objetivo analisar a contribuição da Consultoria Interna de Recursos Humanos para a Gestão nas indústrias catarinenses de grande porte.

\section{Consultoria Interna de Recursos Humanos}

A competitividade organizacional é pautada por estratégias adequadas, ênfase nas pessoas e em suas competências. Para melhorar a performance, as organizações vêm consolidando o papel da Gestão de Pessoas e amplian- 
do a atuação dos profissionais de $\mathrm{RH}$ como Consultores Internos, capazes de potencializar as mudanças, a energia e o conhecimento das pessoas, melhorar a estruturação organizacional, a velocidade e a qualidade.

A Consultoria Interna teve origem na Europa e nos Estados Unidos na década de 1950, ganhando forças até chegar a ser, nos anos 80, o segmento que mais crescia entre as modalidades de Consultoria. Consolidou-se na década de 90, em virtude da demanda por mudanças culturais, estruturais e práticas para a competitividade organizacional (JOHRI; COOPER; PROKOPENKO, 1998).

No Brasil, essa forma de atuar evoluiu a partir da década de 60, motivada pela expansão do parque empresarial, necessidade de atualização das técnicas de gestão organizacional, evolução tecnológica, orientação das organizações para o futuro, busca pela melhoria no conhecimento das pessoas e um questionamento progressivo da relação organização-cliente, visando um processo de melhoria contínua e sustentada (OLIVEIRA, 1999).

Dessa maneira, a Consultoria Interna tem assumido papel importante nas organizações como atividade de cunho intelectual, de apoio à gestão e à agilidade das ações da organização. Com uma visão sistêmica, atua em mudanças culturais, estruturais, tecnológicas, comportamentais e de organização do trabalho. Há evidências de que a necessidade de reestruturação e modernização das organizações tem aberto maior espaço para determinados especialistas, como os profissionais da área de Recursos Humanos, caracterizados como Consultores Internos (MANCIA, 1997).

Como parte da Gestão de Pessoas, a Consultoria se desenvolveu no meio organizacional na medida em que a área de Recursos Humanos passou de técnico-burocrática para humana e desenvolvimentista, atuando efetivamente nos processos de Recrutamento e Seleção, Treinamento e Desenvolvimento, Cargos e Salários, entre outros. Assim, a necessidade de mudança nos processos, nos sistemas organizacionais e na verdade conduzida pelos colaboradores das organizações ampliou de forma significativa a importância da Consultoria para a área de Gestão de Pessoas. A evolução tecnológica e a ênfase na qualidade também foram aspectos que contribuíram para que as atividades de Consultoria fossem percebidas como ações estratégias, que possibilitam a melhoria da Gestão de Pessoas e o desenvolvimento organizacional, por meio de visões agregadoras ao negócio da organização (LEITE et al., 2005).

A missão da área de $\mathrm{RH}$ é, por exemplo, apoiar os gestores de linha para ter profissionais qualificados (Recrutamento e Seleção), motivados e 
produtivos (Avaliação de Desempenho e Recompensa). Para isso, os profissionais de $\mathrm{RH}$ precisam estar próximos de seus clientes internos para orientálos e apoiá-los constantemente, por meio de informações ou de ações, em uma relação de parceria. Dessa parceria surge a função do $\mathrm{RH}$ de prestar Consultoria, facilitando a manutenção da flexibilidade organizacional e pesquisando novos modelos que otimizem a articulação dos recursos da empresa, preparando-a para mudar e se adaptar aos desafios do ambiente (CÂMARA; GUERRA; RODRIGUES, 1997).

Milkovich e Boudreau (2000) apontam que algumas organizações atuam com um modelo de $\mathrm{RH}$ de alta flexibilidade, com líderes dotados de ampla experiência e conhecimento sobre o negócio e suas unidades. Nesse modelo, a ação fica por conta dos gestores ou representantes de $\mathrm{RH}$, os quais atuam como Consultores Internos para as unidades de negócio, criando políticas adequadas às necessidades de cada unidade e transformando a organização em uma rede de alianças.

Com isso, a evolução da área de $\mathrm{RH}$, dentro dos seus diversos modelos de gestão até a Consultoria Interna de Recursos Humanos, pode ser observada através do Quadro 1.

\begin{tabular}{|c|c|c|c|}
\hline Modelo/A ção & $\begin{array}{l}\text { Administração } \\
\text { de Pessoal }\end{array}$ & $\begin{array}{l}\text { Administração de } \\
\text { Recursos Humanos }\end{array}$ & $\begin{array}{l}\text { Consultoria Interna } \\
\text { de Recursos Humanos }\end{array}$ \\
\hline $\begin{array}{l}\text { Concepção sobre } \\
\text { as pessoas }\end{array}$ & $\begin{array}{l}\text { Policiamento, } \\
\text { mandatário }\end{array}$ & $\begin{array}{l}\text { Valorização das } \\
\text { experiências }\end{array}$ & $\begin{array}{l}\text { Valorização das Compe- } \\
\text { tências e do Capital } \\
\text { Intelectual }\end{array}$ \\
\hline Ação de RH & $\begin{array}{l}\text { Controle jurídico, } \\
\text { administrativo e } \\
\text { legal }\end{array}$ & $\begin{array}{l}\text { Atuação mediante } \\
\text { especialidades }\end{array}$ & $\begin{array}{l}\text { Orientação para a } \\
\text { obtenção dos resultados } \\
\text { estratégicos da empresa }\end{array}$ \\
\hline Políticas de RH & Inexistentes & $\begin{array}{l}\text { Implícitas, algumas } \\
\text { vezes formalizadas }\end{array}$ & $\begin{array}{l}\text { Explícitas, formalizadas } \\
\text { e diretamente relaciona- } \\
\text { das aos resultados } \\
\text { estratégicos }\end{array}$ \\
\hline Sistemas & $\begin{array}{l}\text { Relacionados com } \\
\text { exigências legais e } \\
\text { ao pagamento de } \\
\text { salários }\end{array}$ & $\begin{array}{l}\text { Baseados na utiliza- } \\
\text { ção de várias } \\
\text { técnicas de Adminis- } \\
\text { tração de RH }\end{array}$ & $\begin{array}{l}\text { Sofisticados, articulados } \\
\text { com a obtenção dos } \\
\text { resultados estratégicos } \\
\text { da empresa }\end{array}$ \\
\hline Status & $\begin{array}{l}\text { Subordinado a } \\
\text { uma gerência } \\
\text { média }\end{array}$ & $\begin{array}{l}\text { Subordinado a uma } \\
\text { média ou alta } \\
\text { gerência }\end{array}$ & $\begin{array}{l}\text { Subordinado ao principal } \\
\text { executivo ou parte integran- } \\
\text { te de grupo dirigente }\end{array}$ \\
\hline
\end{tabular}

Quadro 1: Os modelos de RH até a Consultoria Interna de Recursos Humanos.

Fonte: Orlickas (1999). 
A conceituação da Consultoria é ampla na literatura, porém, é possível observar uma relação entre os conceitos, no que diz respeito a sua concepção como atividade de parceria entre a organização e um profissional apto a orientar, a gerar mudanças e a desenvolver soluções capazes de agregar valor à organização.

Partindo de uma definição geral de Consultoria, Orlickas (1999) a define como o fornecimento de certa prestação de serviço, por um profissional qualificado, provido de remuneração, efetuada por meio de diagnósticos e processos, com o propósito de levantar as necessidades organizacionais, indicar soluções, recomendar ações, efetivamente implantá-las e acompanhálas. A autora pondera que entre as diversas formas da Consultoria, figura a Consultoria Interna de Recursos Humanos. Algumas definições sobre o tema são expostas no Quadro 2.

\begin{tabular}{|l|l|}
\hline Orlickas (1999) & $\begin{array}{l}\text { Processo que exige a atuação multidisciplinar do profissional de RH } \\
\text { na organização, como elo entre o cliente interno e o RH corporativo } \\
\text { e agente facilitador que efetua levantamentos e diagnósticos, ofere- } \\
\text { ce sugestões e busca soluções. }\end{array}$ \\
\hline Gil (2001) & $\begin{array}{l}\text { Prestação de serviços focados na identificação e análise de proble- } \\
\text { mas relacionados à política, organização e métodos na área de RH } \\
\text { e recomendação de ações preventivas e corretivas à organização. }\end{array}$ \\
\hline Leite et al. (2005) & $\begin{array}{l}\text { Intervenção planejada na organização e nos seus processos de mu- } \\
\text { dança, que afeta diretamente as pessoas, os grupos e a própria } \\
\text { coletividade. }\end{array}$ \\
\hline França (2007) & $\begin{array}{l}\text { Função de Recursos Humanos onde são realizadas atividades de } \\
\text { apoio, orientação e supervisão para as demandas da organização. }\end{array}$ \\
\hline
\end{tabular}

Quadro 2: Definições de Consultoria Interna de Recursos Humanos.

Fonte: Elaborado pelos autores.

É possível observar nessas definições, referências à consultoria Interna de $\mathrm{RH}$ como uma ação de apoio à solução de problemas organizacionais. Outros dois pontos importantes ressaltados são o caráter de agente facilitador do Consultor Interno de RH (ORLICKAS, 1999) e a questão da mudança organizacional que pode ser gerada pela consultoria Interna de RH (LEITE et al., 2005).

Leite et al. (2005) argumentam que a CIRH agrega valor à Gestão de Pessoas, pois focaliza os meios pelos quais os resultados são atingidos, gerenciando as pessoas envolvidas de modo efetivo. 
Wanderley (1992) observa que o Consultor Interno de RH representa a evolução da Auditoria de Recursos Humanos, cumprindo papel de fiscalizador e de mantenedor do desempenho organizacional.

Como processo de apoio à Gestão de Pessoas, a Consultoria contempla a valorização do trabalho do Consultor Interno e a transformação da função de RH em função estratégica, ficando a Gestão de Pessoas a cargo dos Gestores de Linha (LEITE et al., 2005). Eltz e Veit (1999, p. 34) argumentam que

[...] a atividade de Consultoria requer de seus profissionais e usuários uma complementaridade integrativa, na qual a efetividade do processo se dá na medida em que existem ações que objetivam abolir os limites das posições individuais e propiciar a sinergia na busca de soluções.

O Consultor Interno de RH atua como orientador da organização, em um processo de responsabilidade compartilhada e de desenvolvimento coletivo. A Consultoria Interna de RH é caracterizada a seguir.

A Consultoria Interna é uma alternativa para o desenvolvimento organizacional, que visa responder com agilidade e inteligência às demandas da organização (MANCIA, 1997). Ela agrega valor à organização, pois se trata de um agente interno que conhece os problemas da empresa (ROFFEY PARK, 2003), um parceiro estratégico, que contribui de modo criativo para a produtividade e eficácia da organização (GREEN, 2002).

Desse modo, o objetivo final da Consultoria Interna é produzir "alguma espécie de mudança" (BLOCK, 2001, p. 3), seja de estrutura, políticas, procedimentos ou relacionamento. Mais especificamente, há três tipos de objetivos: objetivos de negócio, objetivos de aprendizagem e objetivos de desenvolvimento organizacional (BLOCK, 2001).

Dessa forma, a Consultoria Interna proporciona mudanças na organização e soluciona problemas de seus setores sem a necessidade de criação de assessorias permanentes ou de contratação de serviços externos (consultoria externa). Já o Consultor Interno influencia, aconselha e persuade as pessoas a fazer as coisas de modo diferente (JOHRI; COOPER; PROKOPENKO, 1998).

Orlickas (1999) e França (2007) apontam que a Consultoria Interna de $\mathrm{RH}$ visa monitorar rapidamente os focos de insatisfação, atender a maioria das necessidades dos colaboradores e gerar proximidade entre cliente e con- 
sultor, maior interação e criação de uma relação de confiança, menor custo fixo e maior facilidade na avaliação e controle do trabalho efetuado. Ainda na visão de Orlickas (1999), a CIRH busca melhor atender o cliente interno, prover a organização de informações descentralizadas, facilitar a comunicação organizacional e antecipar tendências, tudo isso alinhada com as estratégias da organização.

A Consultoria Interna busca no profissional de $\mathrm{RH}$ o entendimento dos movimentos organizacionais provenientes das mudanças internas ou externas e o suporte às áreas e gestores na busca dos resultados estabelecidos. Atua na cultura, planejamento estratégico, gerenciamento e assessoria, em todos os níveis da organização, buscando ligar as atividades de cada unidade com os objetivos estratégicos. As suas ações devem orientar as áreas no alcance dos objetivos estratégicos, identificando as interações que podem e devem ser fortalecidas. Portanto, exigem da estrutura de $\mathrm{RH}$ capacidade de comunicação, multifuncionalidade e visão sistêmica amplamente desenvolvida (AMORIM, 2003).

Para assegurar o alcance dos objetivos e as contribuições da Consultoria Interna de $\mathrm{RH}$, a relação do profissional com a organização é aspecto pontual. Oliveira (1999) argumenta que a interação do Consultor Interno de RH com a organização deve ser sólida e bem planejada, sustentada pela confiança, otimização de informações, abertura a mudanças e visão do Consultor como um facilitador, para que o trabalho seja desenvolvido com maior eficácia. Este deve atuar como um agente de desenvolvimento organizacional, capaz de desenvolver comportamentos, atitudes e processos que possibilitem uma mudança planejada, visando uma melhor adequação ao mercado, à tecnologia e ao ritmo dinâmico de mudanças no ambiente organizacional global.

Em complemento, Hansen (1990) expõe sobre o grau de envolvimento do Consultor Interno no processo de mudança organizacional, o qual varia de acordo com as necessidades e a Cultura Organizacional. A participação ativa envolve o seu domínio como especialista, buscando soluções e fazendo recomendações, baseado no seu conhecimento e experiência, e a implementação das suas recomendações pela empresa. A participação passiva do Consultor Interno posiciona-o como educador/orientador da organização, para que ela possa conduzir o processo ou resolver os problemas que surgem, não centrando as soluções na figura do Consultor. Seja qual for o grau de envolvimento do Consultor, esse envolvimento é fonte de aprendizado, segurança e otimização de resultados. 
Mesmo com todo cuidado na relação do Consultor com a organização, a resistência das pessoas a mudanças é fator presente. Block (2001) pondera que o ponto central para a compreensão da resistência é vê-la como uma parte previsível, natural e necessária da aprendizagem organizacional. Tratase de uma reação emocional contra o processo de estar recebendo auxílio ou de precisar encarar problemas organizacionais. $\mathrm{O}$ autor cita que o Consultor deve apoiar a organização para que expresse a sua resistência e trabalhe a questão da mudança.

Já Leite et al. (2005) avaliam a mudança como uma variável de cunho psicológico/comportamental, a ser trabalhada de forma a amenizar ou eliminar a instabilidade emocional, os medos e as expectativas experimentados pelos indivíduos. Para atingir os objetivos propostos pela Consultoria Interna de $\mathrm{RH}$, o Consultor deve considerar também a cultura individual, a experiência profissional, a pressão social e o histórico organizacional como fatores determinantes do tipo e do ritmo das mudanças organizacionais, agindo como um facilitador dos processos de mudança.

Visto isso, a Consultoria deve respeitar a realidade e a dinâmica organizacional, atuando da forma mais viável à realidade da organização, concentrando-se na mudança gradual, permitindo a ampliação da visão da empresa, o aprofundamento do seu conhecimento e a adaptação ao ambiente. Deve-se entender o contexto, definir o foco, planejar a gestão (Consultoria), selecionar as ferramentas e processos e assegurar o seu controle (LEITE et al., 2005). Esses aspectos são determinados no projeto da Consultoria Interna de $\mathrm{RH}$.

Esse contexto determina que o profissional de Recursos Humanos como Consultor Interno apresente características essenciais. Em termos gerais, Green (2002) indica que a Consultoria Interna de RH exige um conjunto de conhecimentos definidos, mudança de atitudes e uma nova forma de pensar o $\mathrm{RH}$.

Na visão de Block (2001), o Consultor Interno de RH precisa ter Habilidade Técnica, a qual envolve especialização em determinada área, Habilidade Interpessoal, tratando da comunicação e relacionamento, e Habilidade de Consultoria, situada na competência, no cumprimento e na execução de todas as fases do projeto de Consultoria.

Vergara e Branco (1995) apontam um perfil que envolva competências gerenciais para gerir a competitividade, a complexidade, a incerteza, a adaptabilidade e o aprendizado. Milkovich; Boudreau (2000) e Ulrich (2000) ressaltam que, como parceiro de negócio e agente de mudanças, o Consultor 
deve conhecer profundamente o negócio da empresa, em termos financeiros, estratégicos, tecnológicos e organizacionais, além das práticas específicas de RH, tornar-se especialista administrativo, defensor dos colaboradores e desenvolver a liderança, a comunicação, os sistemas de incentivo e a responsabilidade coletiva.

Na perspectiva de Gil (2001), a atuação do gestor de pessoas é estratégica, consultiva, preventiva e de parceria. Focado nas soluções e no cliente, busca a renovação cultural e tecnológica, por meio do planejamento de longo prazo, benchmarking, gestão de talentos, liberdade das pessoas, qualidade de vida no trabalho, manutenção da ética e responsabilidade social, como um agente de mudanças.

Em uma síntese, o perfil do Consultor Interno de $\mathrm{RH}$, de acordo com diversos autores, é pautado pela visão de administração e de mercado, visão generalista ou especialista conforme o foco e o nível de intervenção, pelo pensamento estratégico, por habilidades de negociador, líder e educador, ênfase nas pessoas, racionalidade e isenção, disciplina, criatividade, perseverança, habilidade para assumir riscos e enfrentar resistências, comprometimento com os resultados e comportamento ético (MOCSÁNYI, 1997; ELTZ; VEIT, 1999; JUNQUEIRA, 1999; OLIVEIRA, 1999; ORLICKAS, 1999; LEITE et al., 2005).

No que concerne à equipe da Consultoria, ela deve predefinir o líder, o facilitador do projeto e o assistente do projeto. A observação e o cumprimento de tais premissas tornam um projeto coerente com a demanda da organização e estabelecem uma estrutura horizontalizada, cujas competências são reunidas para agregar resultados a todas as áreas envolvidas na Consultoria (LEITE et al., 2005).

A monitoração da Consultoria Interna de $\mathrm{RH}$ é aspecto preponderante para a avaliação, por parte da organização, do suporte oferecido pela Consultoria, da verificação da coerência com o planejamento realizado e das ações propostas e implementadas. Nesse sentido, Leite et al. (2005) apresentam um posicionamento sobre o controle do projeto da Consultoria, defendendo que isso deve ocorrer durante toda a sua realização, para que o Consultor tenha informações constantes e atualizadas e possa assegurar o alcance dos objetivos da Consultoria. Como forma de controle, coloca o Ciclo do PDCA, ferramenta utilizada na Gestão da Qualidade, sendo P (plan) - Planejar, D (do) - Executar, C (check) - Verificar e A (act) - Agir corretivamente. 
O planejamento da $\mathrm{CIRH}$, a obediencia ao projeto e aos seus fatores inerentes e a manutenção das ações resultantes do trabalho do Consultor qualificam a Consultoria como ferramenta apoiadora das estratégias organizacionais e de transformação da organização. As formas de intervenção da Consultoria Interna de Recursos Humanos são o teor do próximo subitem.

O Consultor Interno de $\mathrm{RH}$ é um intraempreendedor, capaz de gerar conhecimento, qualidade, flexibilidade e inovação à organização, por meio de processos de Recursos Humanos alinhados às estratégias organizacionais e de programas voltados ao desenvolvimento da empresa e das pessoas. A Consultoria Interna de $\mathrm{RH}$ é uma atividade atrelada ao planejamento organizacional, pois, para Orlickas (1999), o Consultor, possuindo o conhecimento de uma realidade mais ampla, ajuda os gestores a produzir excelência.

A prática da Consultoria Interna de Recursos Humanos focaliza no capital humano, pois, independente do nível que for agir, a transformação da organização está relacionada ao desempenho das pessoas. Orlickas (1999) ressalta, nesse ponto, a Consultoria de Performance Humana, um modelo sistêmico, aplicável em diversas situações organizacionais, uma forma sinérgica de solucionar problemas e de aumentar a produtividade, que permite a visão do beneficio global para a organização, envolvendo as pessoas na gestão da mudança. Sua perspectiva é de que as pessoas tenham o desempenho no trabalho diretamente vinculado à Cultura e estrutura organizacional, aos objetivos, processos organizacionais, ao ambiente de trabalho, recursos, prioridades e normas e práticas de gestão, portanto, o Consultor considera a organização em termos de negócio do cliente, performance, aprendizagem e ambiente de trabalho, o que possibilita que ele possa definir as intervenções.

Nesse sentido, Guimarães (2005) e Leite et al. (2005) corroboram os aspectos éticos da Consultoria Interna de $\mathrm{RH}$, acrescentando na conduta ética do Consultor o compromisso em assumir e executar atividades para as quais tenha competência, prestar assistência ao cliente na melhoria do seu desempenho e atuar como agente de mudanças voltado à cidadania. Guimarães (2005) sintetiza que a aprendizagem e o desenvolvimento organizacional dependem da ação e conduta éticas. O Consultor é responsável pela construção de certos paradigmas organizacionais, deve ser um modelo de comportamento para a organização, então seu trabalho guia-se pelo profissionalismo, confiabilidade e pela parceria. 
Dante Marciano Girardi - Édis Mafra Lapolli - Kelly Cristina Benetti Tonani Tosta

A Consultoria Interna de Recursos Humanos é resultante da evolução da área de $\mathrm{RH}$ e atua como ferramenta estratégica de mudança, agregando valor significativo às organizações por meio da valorização humana, gerando conhecimento, desenvolvimento compartilhado e competitividade.

\section{Procedimentos Metodológicos}

Para os fins a que se propõe este estudo, os procedimentos metodológicos seguiram a linha da pesquisa qualitativa, por meio das técnicas de pesquisa descritiva e aplicada.

Dessa forma, esta pesquisa visa analisar a interação da Consultoria Interna de Recursos Humanos e a Gestão do Conhecimento, de forma descritiva e analítica, preocupando-se com o processo de congruência entre essas variáveis.

A contribuição da Gestão do Conhecimento para a Consultoria Interna de Recursos Humanos será tratada qualitativamente, enquanto processo de melhoria organizacional, em que serão descritos os aspectos referentes à cada organização em particular. Isso permite que seja feita uma análise do comportamento desse processo de forma sistêmica no contexto empresarial pesquisado, por meio do conteúdo exposto (interpretações, mensagens) pelos sujeitos das organizações pesquisadas.

Este estudo tem como população as empresas industriais catarinenses de grande porte. Esse recorte se deve à necessidade da organização ter uma estrutura de $\mathrm{RH}$ constituída e um porte que permita investimentos significativos na área de $\mathrm{RH}$ e a possibilidade de descentralização, essência da Consultoria Interna.

Para tanto, foi utilizada uma listagem de indústrias de grande porte, fornecida pela FIESC - Federação das Indústrias do Estado de Santa Catarina, de onde foram extraídas as dez empresas com maior número de colaboradores.

Sendo assim, conforme o tamanho dessas empresas, foi adotada uma amostra intencional de dez delas, a fim de levantar o estágio em que se encontra a Consultoria Interna de Recursos Humanos.

Em conseguinte, foi obtida a listagem mostrada no Quadro 3. 


\begin{tabular}{|l|c|}
\hline \multicolumn{1}{|c|}{ Empresa } & $\mathbf{N}^{\mathbf{0}}$ de colaboradores \\
\hline AURORA - COOPERATIVA CENTRAL OESTE CATARINENSE & 27508 \\
\hline WEG & 14420 \\
\hline SADIA & 13109 \\
\hline PERDIGÃO AGROINDUSTRIAL S/A & 12407 \\
\hline BUSSCAR ÔNIBUS S/A & 9707 \\
\hline TUPY S.A. & 7500 \\
\hline MALWEE MALHAS LTDA & 7500 \\
\hline WHIRLPOOL S/A - MULTIBRÁS & 6000 \\
\hline TEKA TECELAGEM KUEHNRICH S/A & 5950 \\
\hline WHIRLPOOL S/A - EMBRACO & 5400 \\
\hline
\end{tabular}

Quadro 3: Empresas que compõem a amostra.

Fonte: Elaborado pelos autores.

Os sujeitos de pesquisa foram os gestores responsáveis pela área de Gestão de Pessoas ou Recursos Humanos de cada empresa, podendo ampliar para outros gestores de processos ou ainda, caso houver, o gestor de Consultoria Interna.

O tamanho da amostra foi determinado pelo fato de que não há a intenção de generalização dos dados, com abordagem quantitativa, mas de obter uma análise qualitativa, com maior profundidade. Portanto, seria inviável a realização da pesquisa em um número superior de empresas.

Das dez empresas, foram entrevistadas sete devido à disponibilidade das mesmas. Cinco empresas responderam pessoalmente as entrevistas e duas responderem por correio eletrônico. Por motivo de sigilo, não são identificadas as empresas na análise.

A técnica de análise de conteúdo utilizada nesta pesquisa foi a análise por categoria, a qual, segundo Richardson (1989), consiste na classificação e na quantificação dos elementos contidos nas mensagens, tais como as palavras ou símbolos, as frases ou orações, o tema, o ator (sujeito da ação) e o documento ou item.

Por meio dessa técnica foi identificado o estágio atual do processo de Consultoria Interna de Recursos Humanos, bem como o seu impacto nos resultados das empresas a serem estudadas. 
Dante Marciano Girardi - Édis Mafra Lapolli - Kelly Cristina Benetti Tonani Tosta

Para análise, foi utilizada a documental, e as entrevistas foram analisadas por meio da técnica de análise do discurso que, segundo Vergara (1997), é um método que visa não só apreender como uma mensagem é transmitida, como também explorar o seu sentido. Portanto, a análise do discurso inclui o contexto no qual ele está inserido e não considera somente o que se fala, mas como se fala.

\section{Consultoria Interna nas Organizações Estudadas}

Aqui foram analisados os dados que se referem à Consultoria Interna de Recursos Humanos de um modo geral e a importância da descentralização do RH nas organizações, incluindo os aspectos sobre como pode ser criado o conhecimento nesse sentido.

Na Empresa 1, a consultoria interna é tratada como uma estratégia corporativa dentro da organização, tratando o assunto com a denominação de business partner, sendo que o objetivo desse programa, de acordo com o Entrevistado 1, é "dar o suporte a cada diretoria e ser ponto de referência para identificar as necessidades e traduzir aqui também nas demandas nossas".

Esse programa faz parte de todas as unidades da empresa, e os consultores são catalisadores dos processos, passando as informações necessárias, resolvendo o que é possível para atender de forma geral o processo, auxiliando na tomada de decisão. Mas é relatado que os consultores ainda não têm autonomia plena do processo, trabalhando mais como facilitadores.

Cabe destacar que tudo isso é registrado e armazenado, a fim de auxiliar na geração de conhecimento na empresa. Esse ponto auxilia na socialização do conhecimento proposta por Nonaka e Takeuchi (1997).

Os entrevistados da Empresa 1 ainda enfatizam que esse processo ainda não atingiu um nível de maturidade, mas está sendo trabalhado para isso.

Para ter maior receptividade a esse programa, são feitos treinamentos periódicos com os gestores, por meio de programas voltados a liderança na Empresa 3, bem como MBA in company, com foco no desenvolvimento comportamental.

São definidas as competências necessárias aos líderes da organização, assim como a avaliação dos líderes, para que os gaps sejam solucionados por meio de treinamentos e desenvolvimentos, promovendo também a 
integração entre líderes. Desse modo, percebe-se a tendência descrita como gestão por competências na Empresa 1.

Já na Empresa 2, a função de consultor interno é mais limitada, quase nula, o que se percebe é uma participação dos gestores em alguns processos de recursos humanos, como por exemplo, a seleção.

Por outro lado, a Empresa 3 utiliza fortemente o conceito de consultor interno, como um facilitador da área de recursos humanos. Essa mudança aconteceu por meio da descentralização da área e isso pode ser percebido por meio da fala do Entrevistado 3,

[...] facilitador, consultor, do meio do negócio. Porque hoje nós temos bem descentralizado, mas bem descentralizado, se analisar nosso sistema, nosso portal, o gestor hoje faz tudo, e não solicita nada, não se envolve em nada de Recursos Humanos, só quando ele sente dificuldade, há necessidade de alguma consultoria.

É também percebida uma autonomia do consultor e dos gestores, como por exemplo, na contratação de pessoas, sendo que o recrutamento e a triagem são realizados pelo $\mathrm{RH}$, mas a decisão final e a escolha é do gestor.

Para essas atividades há uma preparação dos gestores, buscando, de acordo com o Entrevistado 3, valorizar as "pratas da casa".

Outro ponto a ser destacado é a decisão compartilhada, pois de acordo com o Entrevistado 3 as decisões são tomadas por comissões, "por nós sermos já uma administração bem participativa, é muito forte a decisão por comissão, nosso sistema é todo de comissão, se você for ver assim, essa empresa é muito burocratizada, burocratizada não, tudo é definido em comissões".

Sobre a preparação dos funcionários, para cada funcionário apresentase primeiro a participação em círculos de controle de qualidade (CCQ), depois se participa de comissões, passando posteriormente a ser um facilitador de área, que de acordo com o Entrevistado 3 é "a pessoa que está abaixo da chefia e ajuda no treinamento dos colaboradores, no desenvolvimento dos colaboradores". Como um coaching, sendo formado na base da empresa para futuros cargos de gestão. Esse ponto é corroborado com as tendências de RH apresentadas na fundamentação teórica.

O consultor interno é chamado de analista na Empresa 3, sendo que tal função já está enraizada na empresa de acordo com o Entrevistado 3. Quan- 
to aos analistas, alguns têm conhecimento sobre todo o processo, mais generalistas, outros são especialistas.

Esse sistema foi implementado a partir do ano de 2000 e não foi baseado em nenhuma literatura específica, mas sim de benchmarking e da necessidade do momento da empresa.

É enfatizado pelo Entrevistado 3 que não houve muita resistência na implementação do consultor interno, $e$ isso foi visto como um processo de transição da empresa. "Então, os novos aceitam isso muito mais fácil, e os mais antigos dizem: não precisa eu me viro e depois vão sentindo que de fato precisão disso, então as resistências são poucas".

Para isso, de acordo com o Entrevistado 3, é necessário mostrar que o consultor veio para ajudar, para agregar, tornando-se assim essencial o processo de seleção desse consultor.

Para essa função, é necessário ser ético e admitir quando precisa de ajuda, podendo assim ganhar confiança dos gestores e conseguir realizar uma gestão compartilhada com eles. É importante saber que há um canal aberto de comunicação, tanto com o consultor como com o RH.

Assim, pode-se fazer o planejamento por meio do levantamento das necessidades reais da base da empresa. O Entrevistado 3 relata que, quando a necessidade vem realmente da base, a direção atende mais facilmente às solicitações, beneficiando assim todos no processo.

Essas informações são registradas e utilizadas também para decisões futuras. No começo, o processo e as informações tinham que ser mais repetidos e enfatizados, mas com o tempo isso se tornou parte da empresa.

No que tange à Empresa 4, nota-se que em função da criação da área de Gestão Corporativa mencionada anteriormente, o $\mathrm{RH}$ dessa organização vem passando por um importante processo de mudança. Esse processo trouxe a implementação de diversas melhorias, entre elas a estruturação de consultorias internas, chamadas business partners, assim como na Empresa 1, tanto para o RH quanto para a área de Gestão, capacitando pessoas para assumirem essa função. De acordo com o Entrevistado 4, "hoje a empresa integra estas duas grandes áreas na mesma diretoria: gente e gestão".

A relação do $\mathrm{RH}$ com as outras áreas é regida, segundo o Entrevistado 4, por meio de uma política de Recursos Humanos e procedimentos para cada processo. Uma prática interessante é o comitê de Gestão de Pessoas que se reúne bimestralmente, composto pelos Diretores da empresa que deliberam sobre os principais assuntos estratégicos de $\mathrm{RH}$. Outra fonte de 
interface do $\mathrm{RH}$ com as demais áreas "são os consultores internos de $\mathrm{RH}$ que fazem a ponte entre o corporativo e os clientes internos" (Entrevistado 4).

Considerando a realidade da Empresa 5, é possível perceber que os conceitos da consultoria interna e do $\mathrm{RH}$ descentralizado ainda não foram implementados. Percebe-se pela fala do Entrevistado 5 que os analistas de $\mathrm{RH}$ viajam muito até as unidades da empresa para resolver questões relacionadas à área.

Algumas unidades contam com uma psicóloga para as atividades de recrutamento e seleção e, em poucos casos, com um administrador para as atividades de treinamento e desenvolvimento, e todas as unidades contam com uma pessoa responsável pela folha de pagamento. Porém, na maioria dos casos é o próprio gerente da unidade o responsável pelo $\mathrm{RH}$ na ponta.

Os procedimentos são discutidos com os líderes das unidades e são desenvolvidos padrões e normas de procedimentos para as atividades mais rotineiras, as quais a unidade tem autonomia para desempenhar. É importante destacar que todas as atividades passam por auditorias de qualidade que possuem indicadores de $\mathrm{RH}$ que são analisados quanto ao cumprimento das metas.

Entretanto, segundo a Entrevistada 5, os gerentes

[...] têm total autonomia na unidade, porém é interessante porque sempre tecnicamente eles se reportam a nós (RH). Eles têm essa liberdade de tomar as ações nas unidades $e$ eles sempre buscam resguardo com a gente por quê? Porque tecnicamente é a gente que conversa com essas pessoas, a gente que também tem esse dia a dia com eles, então acaba respingando na gente.

Essa fala demonstra que todos os processos passam pela sede e as unidades prestam contas para que se mantenha o alinhamento e os registros referentes aos processos.

Assim, nessa organização, o RH ainda é centralizado, embora trabalhe de maneira próxima e tenha uma postura participativa em relação às outras áreas, isto é, compreende suas necessidades e as considera em seu planejamento.

A Empresa 6 é, entre as empresas pesquisadas, a que há mais tempo trabalha com a consultoria interna de $\mathrm{RH}$, implementada em 1994 . Hoje, a 
empresa conta com seis consultores internos distribuídos geograficamente $e$ coordenados pela sede.

A função do consultor interno é, segundo documentos internos, de

[...] detectar os interesses e necessidades dos funcionários, empregar eficientemente as informações recebidas visando ao desenvolvimento de estratégias, propondo soluções e aprimorando os produtos oferecidos aos recursos humanos.

Segundo o mesmo documento, esse modelo também tem como objetivo antecipar tendências de $\mathrm{RH}$, ter sua atuação alinhada com suas estratégias e as da organização preservando a orientação corporativa.

O consultor interno da Empresa 6 é um funcionário da empresa, que até então ocupava alguma função na área de Recursos Humanos. Esse profissional é capacitado nas demais atividades, adquirindo multifuncionalidade, o que amplia e fortalece sua atuação.

Percebe-se que o sucesso desse modelo de atuação do RH se deve ao cuidado tido com sua implantação. A Empresa 6 realizou um planejamento situando esse modelo nos objetivos gerais da organização. Outro fator chave foi a conscientização de todos os funcionários quanto ao novo modelo.

Em graus diferentes, todos precisam receber, da forma mais transparente possível, todas as informações referentes à necessidade, ao objetivo e às consequências da realização desse processo.

Isso reduziu significativamente, segundo a empresa, a incidência de conflitos e resistência à mudança.

Somente com as políticas de $\mathrm{RH}$ definidas pelo órgão corporativo, o Consultor Interno terá condições de executar seu trabalho sem muitas interferências. Administrar as exceções tornará o trabalho do Consultor muito mais ágil do que se, em todo momento ele precisar consultar o $\mathrm{RH}$ corporativo (documentos internos). 
A Empresa 6 destaca a importância de que se tenham políticas de $\mathrm{RH}$ bem definidas pelo órgão corporativo para que se implante a consultoria interna. Isso também ESTÁ implícito na fala das Empresas 1, 3 e 5.

Antes da implantação, segundo o Entrevistado 6, o RH ficava sobrecarregado devido ao grande número de funcionários que se dirigiam ao $\mathrm{RH}$ para tirar dúvidas, solicitar documentos, entre outras atividades correlatas e que hoje o consultor interno resolve isso com mais agilidade e atenção. Outro ponto de destaque é que os consultores internos participam do dia a dia do chão de fábrica e por isso conseguem detectar necessidades futuras, possibilitando que o $\mathrm{RH}$ seja proativo e se antecipe aos problemas.

Já a Empresa 7, como demonstra a entrevista, está constantemente trabalhando na melhoria desse processo. Hoje, a questão marcante consiste no alinhamento de práticas entre as unidades.

Nessa organização, o papel do consultor interno está mais vinculado à questão estratégica. Para a Entrevistada 7, o papel é de "ser o ponto focal dos gestores para assuntos mais estratégicos da área, relacionados às práticas de RH". Para cumprir com essa função, os consultores internos apresentam alto grau de autonomia.

As atividades que competem ao consultor interno são de um modo geral demandas rotineiras do cliente interno (tais como desligamentos e treinamentos) e também projetos de melhoria do próprio $\mathrm{RH}$.

O Quadro 4 faz um resumo dessa análise:

\begin{tabular}{|c|c|c|c|c|c|}
\hline Empresa & $\begin{array}{c}\text { Nome } \\
\text { dado à } \\
\text { Consultoria } \\
\text { Interna }\end{array}$ & $\begin{array}{c}\text { Nível de } \\
\text { implan- } \\
\text { tação }\end{array}$ & $\begin{array}{c}\text { Grau de } \\
\text { autonomia }\end{array}$ & $\begin{array}{c}\text { Complexidade das } \\
\text { atividades }\end{array}$ & $\begin{array}{c}\text { Nivel de } \\
\text { atuação e } \\
\text { tomada de } \\
\text { decisão }\end{array}$ \\
\hline $\begin{array}{c}\text { Empresa } \\
1\end{array}$ & $\begin{array}{c}\text { Business } \\
\text { Partner }\end{array}$ & Médio & Alto & $\begin{array}{l}\text { Tarefas baseadas em } \\
\text { normas gerais com } \\
\text { eventuais participações } \\
\text { em decisões estratégicas }\end{array}$ & $\begin{array}{c}\text { Tático/ } \\
\text { Estratégico }\end{array}$ \\
\hline Empresa \\
2
\end{tabular}

Quadro 4: Análise comparativa da consultoria interna.

Fonte: Dados primários. 


\begin{tabular}{|c|c|c|c|c|c|}
\hline Empresa & $\begin{array}{c}\text { Nome } \\
\text { dado à } \\
\text { Consultoria } \\
\text { Interna }\end{array}$ & $\begin{array}{l}\text { Nível de } \\
\text { implan- } \\
\text { tação }\end{array}$ & $\begin{array}{c}\text { Grau de } \\
\text { autonomia }\end{array}$ & $\begin{array}{c}\text { Complexidade das } \\
\text { atividades }\end{array}$ & $\begin{array}{c}\text { Nível de } \\
\text { atuação e } \\
\text { tomada de } \\
\text { decisão }\end{array}$ \\
\hline $\begin{array}{c}\text { Empresa } \\
3\end{array}$ & $\begin{array}{l}\text { Consultoria } \\
\text { Interna }\end{array}$ & Médio & Médio & $\begin{array}{l}\text { Tarefas baseadas em } \\
\text { normas gerais com } \\
\text { eventuais participações } \\
\text { em decisões estratégicas }\end{array}$ & $\begin{array}{l}\text { Tático/ } \\
\text { Estratégico }\end{array}$ \\
\hline $\begin{array}{c}\text { Empresa } \\
4\end{array}$ & $\begin{array}{l}\text { Business } \\
\text { Partner }\end{array}$ & Total & Médio & $\begin{array}{l}\text { Tarefas baseadas em } \\
\text { normas gerais com } \\
\text { eventuais participações } \\
\text { em decisões estratégicas }\end{array}$ & $\begin{array}{l}\text { Tático/ } \\
\text { Estratégico }\end{array}$ \\
\hline $\begin{array}{c}\text { Empresa } \\
5\end{array}$ & Analistas & Médio & Alto & $\begin{array}{l}\text { Tarefas rotineiras, base- } \\
\text { adas em normas claras } \\
\text { e explícitas }\end{array}$ & $\begin{array}{l}\text { Operacional/ } \\
\text { Tático }\end{array}$ \\
\hline $\begin{array}{c}\text { Empresa } \\
6\end{array}$ & $\begin{array}{l}\text { Consultoria } \\
\text { Interna }\end{array}$ & Total & Alto & $\begin{array}{l}\text { Tarefas rotineiras, base- } \\
\text { adas em normas claras } \\
\text { e explícitas }\end{array}$ & $\begin{array}{l}\text { Operacional/ } \\
\text { Tático }\end{array}$ \\
\hline $\begin{array}{c}\text { Empresa } \\
7\end{array}$ & $\begin{array}{l}\text { Business } \\
\text { Partner }\end{array}$ & Total & Alto & $\begin{array}{l}\text { Tarefas baseadas em } \\
\text { normas gerais com even- } \\
\text { tuais participações em } \\
\text { decisões estratégicas }\end{array}$ & $\begin{array}{l}\text { Tático/ } \\
\text { Estratégico }\end{array}$ \\
\hline
\end{tabular}

Quadro 4: Análise comparativa da consultoria interna.

Fonte: Dados primários.

Cabe resgatar neste momento as ideias de Nonaka e Takeuchi (1997) sobre a criação do conhecimento. O modelo está ancorado no pressuposto de que o conhecimento é criado e ampliado por meio da interação social entre o Conhecimento Explícito e o Conhecimento Tácito. A mobilização e a conversão do Conhecimento Tácito são o segredo para a criação do conhecimento, pois o aprendizado efetivo vem da experiência direta. O desenvolvimento do conhecimento organizacional estaria então relacionado à conversão do conhecimento. Os autores colocam que a partir do indivíduo, o conhecimento deve ser compartilhado, desenvolvido em nível de grupo ou divisão, movendo-se em espiral na organização, em uma difusão interativa, pressupondo quatro modos de conversão do conhecimento: 
a) Socialização: compartilhamento e criação do Conhecimento Tácito pela experiênciadireta. Alguns exemplos são o Brainstorming $e$ a interação com clientes, antes do desenvolvimento de produtos.

b) Externalização: essência da criação do conhecimento, articulação do Conhecimento Tácito em conceitos explícitos, por meio de diálogos e reflexões, uso de metáforas, analogias e modelos. Um exemplo é a criação do conceito de um produto.

c) Combinação: sistematização de conceitos para gerar novo conhecimento, pela reconfiguração de informações, adição e classificação do Conhecimento Explícito. São instrumentos desse processo documentos, reuniões, conversas telefônicas ou redes de comunicação, possibilitando, por exemplo, na alta administração, a combinação $e$ a integração do conceito de produto com a visão corporativa.

d) Internalização: incorporação do Conhecimento Explícito ao Conhecimento Tácito. A documentação e o uso de manuais ajudam os indivíduos a internalizarem o que aprenderam, ampliando o seu Conhecimento Tácito e, também, a transferirem esse conhecimento a outros indivíduos. Na prática, é possível registrar as reclamações e dúvidas dos clientes e isso ser aproveitado pela equipe de desenvolvimento de produtos.

Portanto pode-se analisar que as empresas que adotaram os princípios da consultoria interna mais plenamente possuem processos mais desenvolvidos de gestão do conhecimento, com a explicitação e compartilhamento de informações de conhecimento, bem como a combinação dos conhecimentos, agregando experiências dos consultores, do $\mathrm{RH}$ e de todos os envolvidos. Os programas de desenvolvimento (explicados posteriormente) é que serão responsáveis pela internalização desse conhecimento.

Destaca-se também que mesmo não tendo, muitas vezes, os processos formais de gestão do conhecimento, a prática da consultoria interna, auxilia nesses processos, pois envolve mais os funcionários, bem como possibilita uma quebra de barreira de comunicação dentro da empresa. Um dos fatores que influencia é a autonomia dos consultores. Nesse ponto, percebe-se um grande compartilhamento de conhecimento, descrito por Nonaka e Takeuchi (1997). 
Sabbag (2007) propõe níveis de criação do conhecimento, pois na dimensão individual da criação do conhecimento, os aspectos inerentes são a criatividade e a Gestão de Competências, as quais fornecem diagnóstico das habilidades, possibilitando avaliar as carências e a falta de autoconhecimento. Nesse contexto, a ação da área de RH é pontual. Em nível de equipe, o trabalho conjunto, a cooperação e a sinergia dinamizam o confronto de ideias e elevam a criação do conhecimento. No âmbito da organização, a questão cultural é determinante (SABBAG, 2007). Percebe-se a interação dos três níveis (individual, em grupo e na organização). Como exemplo dessa interação tem-se a tomada de decisão relatada pela Empresa 3 por meio de comissões. Essa prática auxilia na construção de conhecimento nos três níveis propostos, assim como cria um movimento cíclico entre os níveis.

Dessa forma, pode-se afirmar que a conexão entre a Gestão de Recursos Humanos, a Consultoria Interna de $\mathrm{RH}$ e a Gestão do Conhecimento é mais visível nas empresas estudas que possuem totalidade na implementação dos preceitos da consultoria interna.

\section{Considerações Finais}

A Consultoria Interna de Recursos Humanos tem sido a maneira encontrada para buscar mais agilidade nos processos de gestão, diante da visão fragmentada e departamental das organizações. Assim, considera-se fundamental o conhecimento a respeito desse tema.

Além disso, é uma nova metodologia de gestão do conhecimento implantada de forma descentralizada nas organizações, redefinindo o processo de gestão de pessoas.

A elaboração desta pesquisa concatena as organizações, e suas conclusões visam à aplicação de sistemas de conhecimento para a tomada de decisão.

Pode-se perceber que das sete empresas analisadas, duas não possuem processos estruturados de consultoria interna. Nas outras empresas, foi percebido também que existem níveis de implementação e grau de autonomia, diferentes.

Somente duas empresas alcançam um nível de tomada de decisão estratégico por parte dos consultores internos.

Empreendendo sob a ótica da criação do conhecimento proposta por Nonaka e Takeuchi (1997), a consultoria interna auxilia principalmente nas 
etapas de socialização e externalização do conhecimento. Além disso, permite uma maior interação nos três níveis descritos em Sabbag (2007), individual, grupal e organizacional, desde que sejam implementadas em sua totalidade, bem como os consultores possuam autonomia nos processos.

Assim, analisando a contribuição da consultoria interna de Recursos Humanos para a Gestão do Conhecimento, pode-se perceber que as empresas que possuem maior grau de autonomia e maior nível de implementação são aquelas que os processos são mais compartilhados, socializados $e$ internalizados pelos funcionários. Portanto, pode-se afirmar que nas empresas analisadas o desenvolvimento dos processos de consultoria interna de $\mathrm{RH}$ catalisam os resultados da Gestão do Conhecimento.

\title{
Human Resources Internal Consulting as a Catalyst Practice for Organizational Knowledge Management
}

\begin{abstract}
This paper examines the contribution of the Human Resources Internal Consulting for Knowledge Management in large scale industries of Santa Catarina. The methodological procedures followed the qualitative methodology, by means of descriptive and applied research. It was interviewed seven of the largest companies in Santa Catarina about number of employees. It were used document and content analysis. As the results, the internal consulting helps mainly in the stages of socialization and externalization of knowledge. In addition, if implemented in its entirety and given autonomy to the consultants, it allows greater interaction at the individual, group and organizational levels described by Sabbag (2007). Thus, it can seen that companies have greater autonomy and higher levels of implementation are those that most processes are shared, socialized and internalized by employees. Thus, it can be said that in the analyzed companies, the development of procedures for internal consulting catalyzes the results of knowledge management in them.
\end{abstract}

Key-words: People management. Human Resources Internal Consulting. Knowledge Management. 


\section{Referências}

AMORIM, P. F. P. de. Modelos da Gestão de Pessoas da claro Digital: desafios na implementação. Porto Alegre. 2003. 90 f. Dissertação (Mestrado em Administração). Universidade Federal do Rio Grande do Sul. Disponível em: <http://www.bibliotecadigital.ufrgs.br>. Acesso em: 11 jun. 2008.

BLOCK, P. Consultoria: o desafio da liberdade. São Paulo: Pearson Education do Brasil, 2001.

CÂMARA, P. B. da; GUERRA, P. B.; RODRIGUES, J. V. Humanator: recursos humanos e sucesso empresarial. São Paulo: Dom Quixote, 1997.

ELTZ, F; VEIT, M. Consultoria Interna: use a rede de inteligência que existe na sua empresa. Salvador: Casa da Qualidade, 1999.

FIESC. Guia web SC: o guia da indústria de Santa Catarina. Disponível em: <http://www.fiescnet.com.br/guiawebsc/>. Acesso em: 10 mai. 2008.

FIGUEIREDO, S. P. Gestão do conhecimento: estratégias competitivas para a criação e mobilização do conhecimento na empresa. Rio de Janeiro: Qualitymark, 2005.

FRANÇA, A. C. L. Práticas de Recursos Humanos: conceitos, ferramentas e procedimentos. São Paulo: Atlas, 2007.

GIL, A. C. Gestão de Pessoas: enfoque nos papéis profissionais. São Paulo: Atlas, 2001.

GREEN, M. E. Internal human resources consulting: why doesn't your staff get it? Public Personnel Management, Washington, v. 31, Primavera, 2002.

GUIMARÃES, M. H. Consultoria e ética: uma reflexão. In: BOM SUCESSO, E. (Org.). Competências em consultoria: a teoria na prática. Rio de Janeiro: Qualitymark, 2005, p. 149-162.

HANSEN, J. et al. Consultoration: concepts and practices. New Jersey: Prentice Hall, 1990. 
JOHRI, H. P.; COOPER, J. C.; PROKOPENKO, J. Managing internal consulting organizations: a new paradigm. Advanced Management Journal, v. 63, n. 4, p. 4-10, Outono 1998. Disponível em: <www.proquest.com>. Acesso em: 27 ago. 2008.

JUNQUEIRA, L. A. C. Cada empresa tem o consultor que merece: como otimizar as relações entre clientes e consultores. São Paulo: Editora Gente, 1999.

LEITE, L. A. M. da C. et al. Consultoria em Gestão de Pessoas. Rio de Janeiro: Editora FGV, 2005.

MANCIA, L. T. S. Os desafios do modelo de Consultoria Interna: uma experiência gaúcha. Porto Alegre. 1997. 184 f. Dissertação (Mestrado em Administração). Universidade Federal do Rio Grande do Sul. Disponível em: $<$ http://www.bibliotecadigital.ufrgs.br/da.php?nrb $=000098516 \&$ $l o c=2006 \& \mathrm{l}=\mathrm{a} 6594432 \mathrm{a} 6 \mathrm{dd} 346 \mathrm{c}>$. Acesso em: 12 jun. 2008.

MILKOVICH, G. T.; BOUDREAU, J. W. Administração de recursos humanos. São Paulo: Atlas, 2000.

MOCSÁNYI, D. C. Consultoria: o que fazer, como vender - marketing, vendas e execução. São Paulo: Editora Gente, 1997.

MOREIRA, D. A. Teoria e prática em Gestão do Conhecimento: pesquisa exploratória sobre consultoria em Gestão do conhecimento no Brasil. Belo Horizonte. 2005. 174 f. Dissertação (Mestrado em Ciência da Informação). Universidade Federal de Minas Gerais. Disponível em: <http:// www.bibliotecadigital.ufmg.br/dspace/bitstream/1843/VALA-6K5NGG/1/ mestrado__daniel_alexandre_moreira.pdf>. Acesso em: 10 jun. 2008.

NONAKA, I.; TAKEUCHI, H. Criação de conhecimento na empresa: como as empresas japonesas geram a dinâmica da inovação. 16. ed. Rio de Janeiro: Elsevier, 1997.

OLIVEIRA, D. P. R. de. Manual de consultoria empresarial: conceitos, metodologia, práticas. 2. ed. São Paulo: Atlas, 1999.

ORLICKAS, E. Consultoria interna de recursos humanos: conceitos,cases e estratégias. 4. ed. São Paulo: Makron Books, 1999. 
Dante Marciano Girardi - Édis Mafra Lapolli - Kelly Cristina Benetti Tonani Tosta

ROFFEY PARK. Research report: organizations fails to gain true values from internal consultants, 2003. Disponível em: < http://www.linkageinc.com/ company/news_evetnts/link_learn_enewsletter/archive/2003/ 06_03_Research_roffey_park.aspx >. Acesso em: 20 ago. 2008.

RICHARDSON, R. J. et al. Pesquisa Social: métodos e técnicas. São Paulo: Atlas, 1989.

SABBAG, P. Y. Espirais do conhecimento: ativando indivíduos, grupos e organizações. São Paulo: Saraiva, 2007.

ULRICH, D. Recursos Humanos estratégicos: novas perspectivas para os profissionais de RH. São Paulo: Futura, 2000.

VERGARA, S. C.; BRANCO, P. D. Competências gerenciais requeridas em ambiente de mudança. Revista Brasileira de Administração Contemporânea - ANPAD, Rio de Janeiro: ANPAD, v. 1, n. 1-10, 1995.

VERGARA, S. M. Projetos e relatórios de pesquisa em administração. São Paulo: Atlas, 1997.

WANDERLEY, J. A. Consultoria interna: mudança à vista. In: Recursos Humanos: foco na modernidade. Rio de Janeiro: Qualitymark Editora, 1992. p. 19-22. 